\title{
Gaussian distribution in current-conduction mechanism of (Ni/Pt) Schottky contacts on wide bandgap AllnGaN quaternary alloy
}

\author{
Engin Arslan, ${ }^{1,2, a)}$ Şemsettin Altındal, ${ }^{3}$ Sertaç Ural, ${ }^{2}$ Ömer Ahmet Kayal, ${ }^{2}$ Mustafa Öztürk, ${ }^{2}$ \\ and Ekmel Özbay ${ }^{2,4}$ \\ ${ }^{1}$ Department of Electrical and Electronics Engineering, Antalya Bilim University, 07190 Antalya, Turkey \\ ${ }^{2}$ Nanotechnology Research Center-NANOTAM, Bilkent University, 06800 Ankara, Turkey \\ ${ }^{3}$ Department of Physics, Faculty of Science, Gazi University, Teknikokullar, 06500 Ankara, Turkey \\ ${ }^{4}$ Electrical and Electronics Engineering, Bilkent University, 06800 Ankara, Turkey
}

(Received 19 June 2018; accepted 17 October 2018; published 5 November 2018)

\begin{abstract}
The current-conduction mechanisms of the as-deposited and annealed at $450{ }^{\circ} \mathrm{C}(\mathrm{Ni} / \mathrm{Pt}) \mathrm{Schottky}$ contacts on AlInGaN quaternary alloy have been investigated in the temperature range of 80-320 K. The zero-bias barrier height $(\mathrm{BH})\left(\Phi_{B 0}\right)$ and ideality factor $(n)$ of them were evaluated using thermionic emission (TE) theory. The $\Phi_{B 0}$ and $n$ values calculated from the $I-V$ characteristics show a strong temperature dependence. Such behavior of $\Phi_{B 0}$ and $n$ is attributed to Schottky barrier inhomogeneities. Therefore, both the $\Phi_{B 0}$ vs $n$ and $\Phi_{B 0}$ vs $q / 2 k T$ plots were drawn to obtain evidence on the Gaussian distribution (GD) of the barrier height at the metal/semiconductor interface. These plots show two different linear parts at low and intermediate temperatures for as-deposited and annealed Schottky contacts. Thus, the mean value of $\Phi_{B 0}$ and standard deviation $\left(\sigma_{0}\right)$ was calculated from the linear parts of the $\Phi_{B 0}$ vs $q / k T$ plots for both samples. The values of the effective Richardson constant $\left(A^{*}\right)$ and mean $\mathrm{BH}$ were obtained from the modified Richardson plots which included the effect of barrier inhomogeneity. These values of Richardson constant and barrier height for as-deposited contacts were found to be $19.9 \mathrm{~A} \mathrm{~cm}^{-2} \mathrm{~K}^{-2}$ and $0.59 \mathrm{eV}$, respectively, at low temperature, but $43.3 \mathrm{~A} \mathrm{~cm}^{-2} \mathrm{~K}^{-2}$ and $1.32 \mathrm{eV}$, respectively, at intermediate temperatures. These values of Richardson constant and barrier height for annealed contacts were found to be $19.6 \mathrm{~A}$ $\mathrm{cm}^{-2} \mathrm{~K}^{-2}$ and $0.37 \mathrm{eV}$, respectively, at low temperature, but $42.9 \mathrm{~A} \mathrm{~cm}^{-2} \mathrm{~K}^{-2}$ and $1.54 \mathrm{eV}$, respectively, at intermediate temperatures. It is clear that the value of the Richardson constant obtained for as-deposited and annealed samples by using double-GD for intermediate temperatures is close to the theoretical value of $\mathrm{AlInGaN}\left(=44.7 \mathrm{~A} \mathrm{~cm}^{-2} \mathrm{~K}^{-2}\right)$. Therefore, $I-V-T$ characteristics for the as-deposited and annealed Schottky contacts in the temperature range of 80-320 K can be successfully explained based on TE theory with double-GD of the BHs. Published by the AVS.

https://doi.org/10.1116/1.5045259
\end{abstract}

\section{INTRODUCTION}

III-nitride semiconductors' materials have the wide energy bandgap, high-electron saturation velocity, and high breakdown field, and these properties make them as attractive materials for the development of optoelectronic device applications, such as heterojunction field-effect transistors, highelectron mobility transistors (HEMTs), photodiodes, light emitting diodes (LEDs), laser diodes (LDs), and solar cells. ${ }^{1,2}$ The ternary alloys, such as AlGaN, AlInN, InGaN, and quaternary AlInGaN alloys, received a great deal of attention in the past decade due to its possible candidate in several types of device structures, high frequency and high power devices, LEDs, and LDs. ${ }^{3-6}$

In recent years, its versatility in control of the lattice constant and energy bandgap by varying the indium (In) and aluminum (Al) compositions of the AlInGaN alloys provides additional freedom to adjust the strain and bandgap and makes them attractive materials as active layers in visible and ultraviolet LED and LD. ${ }^{6}$ In addition, the spontaneous and piezoelectric polarization field in a pseudomorphically

${ }^{\text {a) }}$ Author to whom correspondence should be addressed: engina@bilkent.edu.tr grown AlInGaN epilayer on a GaN template layer can be controlled by changing the $\mathrm{In}$ and $\mathrm{Al}$ atomic ratio in the AlInGaN epilayer and those properties give a great opportunity for using HEMT structures as a barrier layer. ${ }^{7-9}$ In addition, an HEMT structure, which contains a lattice-matched barrier to the $\mathrm{GaN}$ template layer, can be grown by regulating the In and $\mathrm{Al}$ ratio in the AlInGAN epilayer. ${ }^{3-5}$ These properties give an important opportunity for the realization of the depletion-mode (d-mode) and enhancement-mode (e-mode) operation in GaN-based HEMTs. ${ }^{5}$

Schottky contacts (SCs) are an important part of HEMT as a gate contact or other device applications. In order to construct such devices, it is necessary to understand the properties of the metal/III-nitride materials interface and its influence on the electrical characteristics of Schottky contacts on these materials. The low leakage current and good thermal stability play the main roles in many electronic and optoelectronic devices. ${ }^{7,8}$ The abnormal leakage currents under reverse bias strongly degrade the gate current characteristics and increase the power consumption. ${ }^{9}$ Therefore, a high quality Schottky contact to GaN-based HEMT must be done. 
There are conflicting measurements in the literature especially on the temperature dependence of both the ideality factor $(n)$ and zero-bias barrier height $(\mathrm{BH})\left(\Phi_{B 0}\right)$ in metalsemiconductor type $\mathrm{SCs}$ with and without an interfacial layer. ${ }^{10-15}$ Because the analysis of the forward bias currentvoltage characteristics of these devices based on thermionic emission (TE) theory usually reveals abnormal behavior, such as the increase of $\Phi_{B 0}$ and increase of $n$ with increasing temperature and the nonlinearity of the conventional Richardson plot. ${ }^{16-21}$ Very recently, they showed that the analysis of the forward bias $I-V$ characteristics in the $(\mathrm{Au} /$ $\mathrm{Ti}) / \mathrm{Al}_{2} \mathrm{O}_{3} / \mathrm{n}-\mathrm{GaAs}$ (MIS), $\mathrm{Au} / \mathrm{Bi}_{0.5} \mathrm{Na}_{0.5} \mathrm{TiO}_{3}(\mathrm{BNT})-\mathrm{BaTiO}_{3}$ (BT) $/ \mathrm{n}-\mathrm{GaN}(\mathrm{MIS}), \quad \mathrm{Au} /(0.07$ graphene-doped $\mathrm{PVA}) / \mathrm{n}-\mathrm{Si}$ (MPS), and $\mathrm{Au} / \mathrm{C}_{20} \mathrm{H}_{12} / \mathrm{n}$-Si(MPS) type Schottky barrier diodes based on the TE theory have revealed an abnormal increase of $\Phi_{\mathrm{B} 0}$ and decrease of $n$, respectively, especially at low temperatures. ${ }^{16,22-24}$ They also indicated that the value of $n$ may be much greater than unity, but the value of the effective Richardson constant $\left(A^{*}\right)$ obtained from the slope of the conventional Richardson plot maybe a million times lower than their theoretical value of a semiconductor. In the literature, such behavior of Schottky barrier heights (SBHs) and $n$ with temperature has usually been interpreted on the basis of the existence of the Gaussian distribution (GD) of the SBHs at around a mean value BH due to BH inhomogeneities between a metal and a semiconductor. ${ }^{19-21}$ In other words, at low temperatures, electrons or holes do not have enough energy to pass through the top of SBH, but they can be passed through lower barriers/patches at around mean SBH and that leads to an increase in the current and so $n$. However, at high temperatures, they gain more and more energy to pass the top of $\mathrm{SBH}^{25-27}$

Many researchers have also reported that the thermal annealing affects the electrical properties of Schottky contacts. ${ }^{28-35}$ Khanna et al. ${ }^{31}$ showed that the SBH $(0.65 \mathrm{eV})$ of the $\mathrm{W}_{2} \mathrm{~B}_{5}$-based rectifying contacts on the $\mathrm{n}$-GaN layer increased with an annealing temperature up to $200^{\circ} \mathrm{C}$. Reddy et al. ${ }^{32}$ concluded that a Pt/Mo Schottky contact on the n-type GaN does not seriously suffer from thermal degradation during the annealing process even at $600{ }^{\circ} \mathrm{C}$. On the other hand, Wang et $_{\text {al. }}{ }^{33}$ reported the degradation of Pt contacts on $\mathrm{n}-\mathrm{GaN}$ above $600^{\circ} \mathrm{C}$. In addition, Order et al. $^{34}$ reported that the barrier height of the $\mathrm{ZrB}_{2}$ Schottky contacts on $\mathrm{n}-\mathrm{GaN}$ was changed from $0.80 \mathrm{eV}$ (as-deposited) to 0.70 and $0.6 \mathrm{eV}$ after annealing at 300 and $400{ }^{\circ} \mathrm{C}$ in a nitrogen atmosphere for $20 \mathrm{~min}$, respectively. Miura et al. ${ }^{35}$ investigated the thermal annealing effects of Ni/Au Schottky contact diodes on $\mathrm{n}-\mathrm{GaN}$ and AlGaN/GaN HEMT structures. They found that the most suitable metals for this system are $\mathrm{Pt}$ and $\mathrm{Ir}$ after annealing at $500{ }^{\circ} \mathrm{C}$. They also characterized the Schottky contacts with and without Ni metal, and it was found to play a significant role in the $\mathrm{Ni} / \mathrm{Pt}(\mathrm{Ir}) / \mathrm{Au}$ system in obtaining better quality Schottky contacts. In their study, they applied the $\mathrm{Ni} / \mathrm{Pt}(\mathrm{Ir}) / \mathrm{Au}$ system as a gate electrode in the AlGaN/GaN HEMTs, and they obtained decrements in gate leakage current as well as increments in drain breakdown voltage without degrading the trans conductance of the transistor.
The improvement of the current-transport mechanisms of Schottky contacts on the quaternary AlInGaN alloy is also very important for the AlInGaN/GaN HEMTs and/or other quaternary AlInGaN alloy based device applications. Unfortunately, limited studies can be found about the currenttransport properties of Schottky contacts on the quaternary AlInGaN alloy in the literature. ${ }^{19,36,37}$ Subramaniyam et al. ${ }^{36}$ interpreted the measured $I-V$ characteristics of the $(\mathrm{Ni} / \mathrm{Au})$ InAlGaN/GaN Schottky barrier diode in the temperature range of $295-473 \mathrm{~K}$ by using the GD of barrier heights. On the other hand, Laurent et al. ${ }^{19}$ published a study about the current-transport properties of the Ni Schottky contacts on the AlInGaN quaternary alloy. They proposed that alloy composition fluctuations inherent to low-temperature III-N alloys result in Schottky barrier height inhomogeneity and that the Schottky barrier height follows a Gaussian distribution.

In this study, the possible current-transport mechanisms of the as-deposited and annealed at $450{ }^{\circ} \mathrm{C}(\mathrm{Ni} / \mathrm{Pt} / \mathrm{Au}) \mathrm{SCs}$ on $\mathrm{Al}_{0.87} \mathrm{In}_{0.04} \mathrm{Ga}_{0.09} \mathrm{~N}$ quaternary alloy were investigated in the temperature range of 80-320 K under the forward bias case. The nonideal $I-V$ behavior of these SCs is explained in terms of barrier inhomogeneity assuming that the SBH takes on double-GD. The source of the reduction in $A^{*}$ from the theoretically expected result was also investigated. In addition, the value of $R_{\mathrm{s}}$ and $\mathrm{BH}$ was calculated using the Norde function for each temperature.

\section{EXPERIMENT}

The $\mathrm{Al}_{0.87} \mathrm{In}_{0.04} \mathrm{Ga}_{0.09} \mathrm{~N}$ quaternary alloy was grown on c-plane (0001) double-polished 2 in. diameter $\mathrm{Al}_{2} \mathrm{O}_{3}$ substrate in a low-pressure metalorganic chemical vapor deposition reactor (Aixtron 200/4 HT-S). In the growth process, triethylgallium, trimethylaluminum, trimethylindium, and ammonia precursors were used as $\mathrm{Ga}, \mathrm{Al}$, $\mathrm{In}$, and $\mathrm{N}$ sources, respectively. The surface of the substrate was baked under $\mathrm{H}_{2}$ ambient at $1250{ }^{\circ} \mathrm{C}$ for $12 \mathrm{~min}$. The growth process was continued with the growth of the nominally $50 \mathrm{~nm}$ thick, low temperature $\left(515^{\circ} \mathrm{C}\right) \mathrm{GaN}$ nucleation layer. The undoped, $3 \mu \mathrm{m}$ thick GaN template layer contains two parts that were grown at different growth conditions. The thickness of the first part is $1 \mu \mathrm{m}$ and was grown under $1040{ }^{\circ} \mathrm{C}$ and 300 mbar pressure conditions. Then, the growth continued with the growth of the second part of the GaN template layer. The thickness of the second part is nominally $2 \mu \mathrm{m}$. There is no doping in the GaN template layer. This layer was grown at $1060{ }^{\circ} \mathrm{C}$ and $150 \mathrm{mbar}$. After the growth process of the $\mathrm{GaN}$ template layer, the $85 \mathrm{~nm}$ thick $\mathrm{Al}_{\mathrm{x}} \mathrm{In}_{\mathrm{y}} \mathrm{Ga}_{1-\mathrm{x}-\mathrm{y}} \mathrm{N}$ quaternary alloys were grown at a temperature of $1150{ }^{\circ} \mathrm{C}$ and $30 \mathrm{mbar}$ [Fig. 1(a)]. The molar fractions of the indium and aluminum in the $\mathrm{Al}_{\mathrm{x}} \mathrm{In}_{\mathrm{y}} \mathrm{Ga}_{1-\mathrm{x}-\mathrm{y}} \mathrm{N}$ quaternary epilayer were determined by $\mathrm{x}$-ray diffraction and $\mathrm{x}$-ray photoelectron spectroscopy (XPS) measurements. The $\mathrm{Al}, \mathrm{In}$, and $\mathrm{Ga}$ atomic ratio in the sample, obtained from the XPS measurements, has been approximately found to be $87 \%$ (Al), 4\% (In), and 9\% (Ga), respectively. Furthermore, the atomic compositions of $\mathrm{Al}$, In, and $\mathrm{Ga}$ have been confirmed by the simulation fitting of 


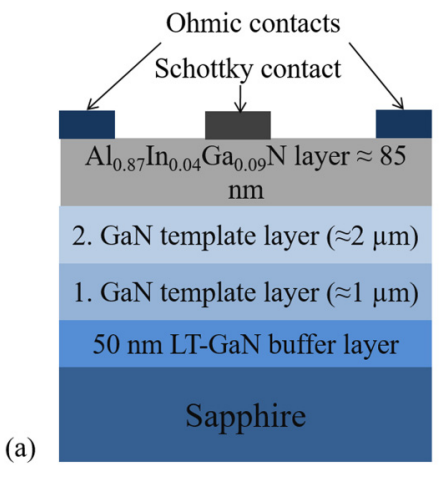

(b)

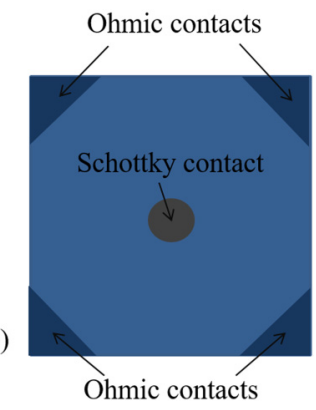

FIG. 1. (a) Schematic diagram of the $\mathrm{Al}_{0.87} \mathrm{In}_{0.04} \mathrm{Ga}_{0.09} \mathrm{~N}$ quaternary alloy on the GaN/LT-GaN/sapphire structure, (b) circular Schottky and square Van Der Pauw ohmic contact on the $\mathrm{Al}_{0.87} \mathrm{In}_{0.04} \mathrm{Ga}_{0.09} \mathrm{~N}$ epilayer surface.

$2 \theta$-scans at an AlInGaN (0002) diffraction pattern using the appropriate Fit software.

The ohmic and Schottky contact fabrication started with cutting and sample cleaning. The wafers were cut into several pieces of $6 \times 6 \mathrm{~mm}$ and treated with isopropyl alcohol and rinsed in deionized (DI) water that possessed $18 \mathrm{M} \Omega$ resistivity. After the cleaning process, the samples were dipped in a solution of $\mathrm{HCl}: \mathrm{H}_{2} \mathrm{O}(1: 1)$ for $30 \mathrm{~s}$ in order to remove the surface oxides and were then rinsed in DI water again for a prolonged period.

The ohmic contact pattern was shaped on the AlInGaN epilayer surface in the square Van der Pauw shape [Fig. 1(b)]. The $\mathrm{Ti} / \mathrm{Al} / \mathrm{Ni} / \mathrm{Au}$ metals were deposited in the thickness ratio of $50 / 120 / 50 / 250 \mathrm{~nm}$, respectively. The metallization was done under a vacuum of $10^{-7}$ Torr and rapid thermal annealing (RTA) of the Ohmic contacts is performed at $800{ }^{\circ} \mathrm{C}$ for $45 \mathrm{~s}$ in $\mathrm{N}_{2}$ ambient. After the formation of the ohmic contact, the Ni/Pt/Au (30/45/300 nm) Schottky contacts were formed by evaporation under a vacuum of $10^{-7}$ Torr. The geometry of the Schottky contacts is a $0.8 \mathrm{~mm}$ diameter circular dot. To study the thermal annealing effects of $\mathrm{Ni} / \mathrm{Pt} / \mathrm{Au}$ contacts on $\mathrm{Al}_{\mathrm{x}} \mathrm{In}_{\mathrm{y}} \mathrm{Ga}_{1-\mathrm{x}-\mathrm{y}} \mathrm{N}$ quaternary alloy, samples were annealed at a temperature of $450{ }^{\circ} \mathrm{C}$ for 15 min in an $\mathrm{N}_{2}$ atmosphere in RTA equipment. The forward and reverse bias $I-V$ characteristics of the $(\mathrm{Ni} / \mathrm{Pt} / \mathrm{Au}) \mathrm{SCs}$ on AlInGaN epilayer for the as-deposited and annealed at $450{ }^{\circ} \mathrm{C}$ samples have been measured in the temperature range of 80 $320 \mathrm{~K}$ using a Keithley model 2400 current-voltage source meter. The atomic ratio of $\mathrm{Al}, \mathrm{In}, \mathrm{Ga}$, and $\mathrm{N}$ in the AlInGaN epilayer was determined using a Rigaku Smart Lab highresolution diffractometer system, delivering CuK $\alpha 1$ (1.544 ^) radiation and the Thermo Scientific K-Alpha XPS system.

\section{RESULTS AND DISCUSSION}

Figures 2(a) and 2(b) show the typical semilogarithmic forward and reverse bias $I-V$ characteristic of the as-deposited and annealed $(\mathrm{Ni} / \mathrm{Pt}) \mathrm{SCs}$ on an AlInGaN epilayer in the temperature range of $80-320 \mathrm{~K}$ by steps of $20 \mathrm{~K}$, respectively.

From Figs. 2(a) and 2(b), it can be seen that the $\ln I-V$ curve contains linear behavior in the forward bias regime at intermediate voltages for both samples and a deviation occurs from the linearity especially due to the effect of $R_{\mathrm{S}}$ in the high voltage region. The $\approx 4$ orders of rectification have been obtained at room temperature for both samples. The measured leakage currents are changed in the range from $1.3 \mathrm{nA}$ (at $80 \mathrm{~K}$ ) to $2.2 \mathrm{nA}$ (at $320 \mathrm{~K}$ ) and $1.4 \mathrm{nA}$ (at $80 \mathrm{~K}$ ) to $3.0 \mathrm{nA}($ at $320 \mathrm{~K}$ ) at $-1 \mathrm{~V}$ for the as-deposited and annealed samples, respectively. It is noted that the leakage current increases with an increase in temperature and they did not go to saturation. The nonsaturation behavior in the reverse bias region can be explained in terms of image force lowering $\mathrm{BH}$, generation-recombination (GR), and the existence of an interfacial layer. $^{18,38-40}$

In order to determine current-transport mechanisms and to calculate $\Phi_{B 0}$ and $n$ of the (Ni/Pt) SCs on AlInGaN quaternary alloy in the forward bias regime at intermediate voltages $(V \geq 3 k T / q)$, the equations that were given based on TE theory were used. ${ }^{18,39}$ It is well known that when a Schottky type contact/diode has $R_{s}$ and the value of $n$ is higher than unity, the forward bias $I-V$ curve in terms of TE theory can be expressed as ${ }^{18,39}$

$$
\begin{aligned}
I & =A A^{*} T^{2} \exp \left(-\frac{q}{k T} \Phi_{B 0}\right)\left[\exp \left(\frac{q\left(V-I R_{S}\right)}{n k T}\right)-1\right] \\
& =I_{o}\left[\exp \left(\frac{q V_{D}}{n k T}\right)-1\right]
\end{aligned}
$$

In Eq. (1), the quantities of $A^{*}, A, T, \Phi_{B 0}, n, R_{\mathrm{s}}, I_{0}$, and $V_{D}$ the effective Richardson constant, contact area, temperature in $\mathrm{K}$, zero-bias barrier height, ideality factor, series resistance, reverse bias saturation current, and voltage drop across the diode, respectively. The theoretical calculations of the Richardson constant for the AlInGaN quaternary alloy with a composition of $87 \%(\mathrm{Al}), 4 \%(\mathrm{In})$, and $9 \%(\mathrm{Ga})$ were calculated via Vegard's law, with AlN, GaN, and InN effective mass values from Ref. 41 . The calculated values for $A^{*}$ were found as $44.7 \mathrm{~A} \mathrm{~cm}^{-2} \mathrm{~K}^{-2}$. Therefore, it is possible to extract the values of $I_{0}, n$, and also $\Phi_{B 0}$ parameter from analyzing $\ln I$ vs $V$ curves as a function of temperature in that the intercept and slope of $\ln I$ vs $V$ plot using Eq. (1) and the theoretical value of $A^{*}{ }^{19-24}$

The experimental $I_{o}, \Phi_{B 0}, n$ and $n T$ values were calculated from intercepts and slopes of the forward bias $\ln I$ vs $V$ graph at each temperature using TE theory. The calculated values of this parameter for the as-deposited and annealed samples are tabulated in Table I. The $I_{o}, n, \Phi_{B 0}$, and $n T$ values for the as-deposited SCs change from $1.2 \mathrm{nA}, 17,0.19 \mathrm{eV}$, and 1394 (at $80 \mathrm{~K}$ ) to $1.7 \mathrm{nA}, 5,0.84 \mathrm{eV}$, and 1815 (at $320 \mathrm{~K}$ ), respectively. On the other hand, the values of the $I_{0}, n, \Phi_{B 0}$, and $n T$ parameters for the annealed SCs change from $0.48 \mathrm{~mA}, 15$, $0.20 \mathrm{eV}$, and 1200 (at $80 \mathrm{~K}$ ) to $3.8 \mathrm{nA}, 5,0.81 \mathrm{eV}$, and 1731 (at $320 \mathrm{~K}$ ), respectively. The $\Phi_{B 0}$ vs $T$ and $n$ vs $T$ plots were given in Figs. 3(a) and 3(b) for both samples.

As can be seen in Table I and Figs. 3(a) and 3(b), the values of the $\Phi_{B 0}$ and $n$ parameters show a strong dependence on temperature. From this graph, one can observe that the experimental values of $\Phi_{B 0}$ increased with increasing 

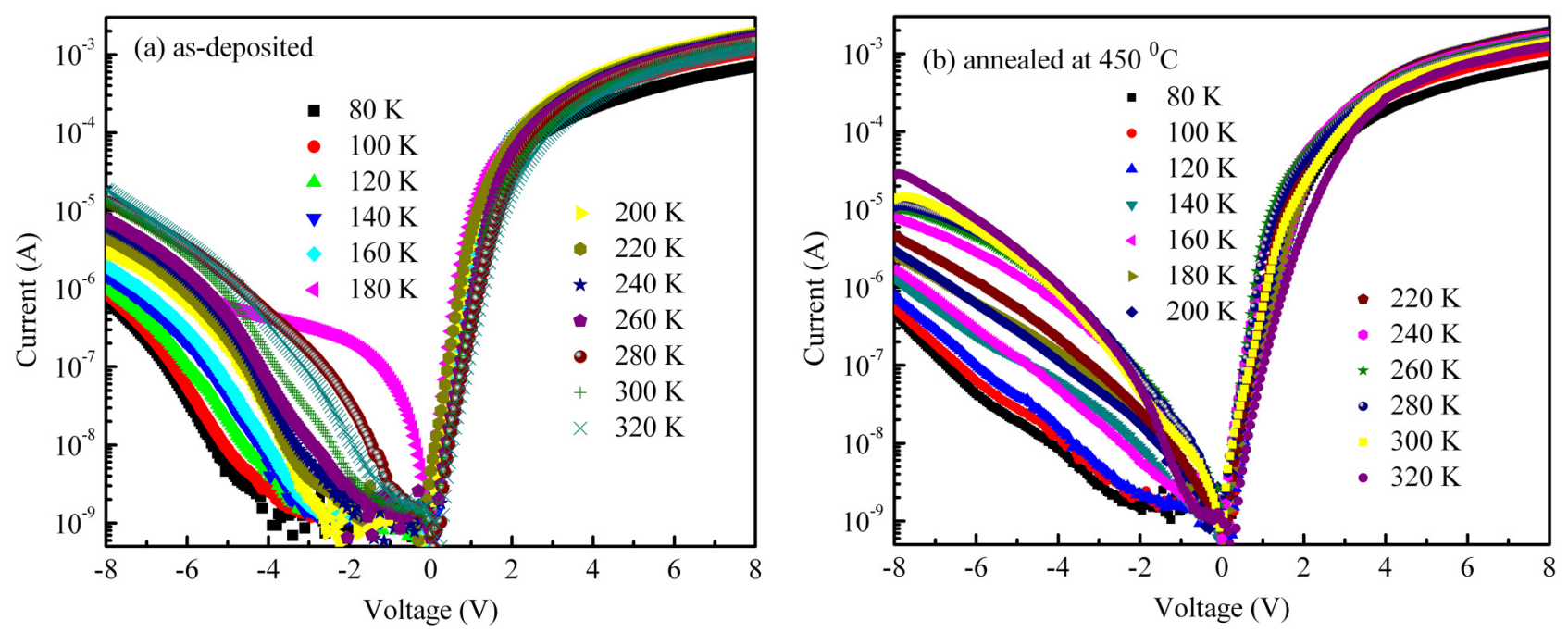

FIG. 2. I- $V$ characteristic of the (Ni/Pt/Au) SCs on AlInGaN quaternary alloy for (a) as-deposited and (b) annealed at $450{ }^{\circ} \mathrm{C}$ at various temperatures.

temperature, while the $n$ decreased with increasing temperature. Such temperature dependent behavior of $\Phi_{B 0}$ and $n$ is defined as a deviation from ideal TE theory. In addition, the $n$ values for the as-deposited and annealed $(\mathrm{Ni} / \mathrm{Pt}) \mathrm{SCs}$ are considerably higher than unity even at room temperature and can be attributed to the high density of interface states, located between the metal and semiconductor, disorder and dangling bonds. As the authors indicated, they are also due to the image force effect, barrier inhomogeneities, or other current-transport mechanisms such as tunneling ${ }^{15}$ or recombination-generation mechanisms. ${ }^{14,30}$ These effects can be passivate using dielectric materials such as $\mathrm{SiO}_{2}, \mathrm{SiN}$, or $\mathrm{HfO}_{2}$ passivation materials, interfacial chemical passivation, ${ }^{42}$ or thermal annealing process. ${ }^{31,32}$

The value of $\mathrm{BHs}$ or activation energy $\left(E_{a}\right)$ is to draw a traditional Richardson plot $\left[\ln \left(I_{o} / T^{2}\right)\right.$ vs $\left.q / k T\right]$ and thereby both the values of $A^{*}$ and $E_{a}$ can be obtained from the intercept point and slope of this plot. According to Eq. (1), the

TABLE I. Temperature dependent values of the parameters of $I_{0}, n, \Phi_{B 0}$, and $n T$ for the as-deposited and annealed SCs on AlInGaN quaternary alloy.

\begin{tabular}{|c|c|c|c|c|c|c|c|c|}
\hline \multirow[b]{2}{*}{$\begin{array}{l}T \\
(\mathrm{~K})\end{array}$} & \multicolumn{4}{|c|}{ As-deposited } & \multicolumn{4}{|c|}{ Annealed at $450^{\circ} \mathrm{C}$} \\
\hline & $\begin{array}{l}I_{0} \times 10^{-9} \\
\text { (A) }\end{array}$ & $n$ & $\begin{array}{l}\Phi_{B 0} \\
(\mathrm{eV})\end{array}$ & $\begin{array}{l}n T \\
(\mathrm{~K})\end{array}$ & $\begin{array}{c}I_{0} \times 10^{-9} \\
\text { (A) }\end{array}$ & $n$ & $\begin{array}{l}\Phi_{B 0} \\
(\mathrm{eV})\end{array}$ & $\begin{array}{l}n T \\
(\mathrm{~K})\end{array}$ \\
\hline 80 & 1.2 & 17 & 0.19 & 1394 & 0.5 & 15 & 0.20 & 1200 \\
\hline 110 & 1.1 & 14 & 0.25 & 1402 & 0.4 & 12 & 0.26 & 1204 \\
\hline 120 & 1.1 & 12 & 0.30 & 1406 & 0.4 & 10 & 0.31 & 1208 \\
\hline 140 & 5.5 & 10 & 0.36 & 1416 & 1.0 & 9 & 0.36 & 1246 \\
\hline 160 & 1.0 & 9 & 0.41 & 1442 & 7.9 & 8 & 0.41 & 1248 \\
\hline 180 & 2.5 & 8 & 0.46 & 1538 & 1.0 & 7 & 0.46 & 1314 \\
\hline 200 & 1.1 & 8 & 0.52 & 1585 & 1.1 & 7 & 0.50 & 1428 \\
\hline 220 & 0.8 & 7 & 0.58 & 1613 & 0.7 & 7 & 0.58 & 1470 \\
\hline 240 & 0.5 & 7 & 0.65 & 1625 & 2.0 & 6 & 0.62 & 1507 \\
\hline 260 & 0.8 & 6 & 0.69 & 1673 & 1.2 & 6 & 0.68 & 1532 \\
\hline 280 & 0.8 & 6 & 0.75 & 1745 & 1.7 & 6 & 0.73 & 1622 \\
\hline 300 & 0.8 & 6 & 0.81 & 1749 & 2.6 & 5 & 0.78 & 1671 \\
\hline 320 & 0.2 & 5 & 0.84 & 1815 & 3.8 & 5 & 0.81 & 1731 \\
\hline
\end{tabular}

$\ln \left(I_{0} / \mathrm{T}^{2}\right)$ vs $q / k_{B} T$ plot should yield a straight line for an ideal Schottky contact, in which the slope gives the barrier height of the contact, and the intercept gives $\ln \left(A^{*}\right)$. However, in our case, $\ln \left(I_{0} / T^{2}\right)$ vs $q / k_{B} T$ plot deviated from the linearity especially and yield a very low value of $A^{*}$ and $\mathrm{BH}$ when compared with their theoretical values due to the barrier inhomogeneities at the metal/semiconductor interface for as-deposited and annealed samples (Fig. 4). Small experimental $A^{*}$ values, high ideality factors, and nonlinearity in conventional Richardson plot $\ln \left(I_{0} / T^{2}\right)$ vs $q / k_{B} T$ and the temperature dependent SBHs are all evidence of barrier inhomogeneities in the $(\mathrm{Ni} / \mathrm{Pt})$ Schottky contact on the AlInGaN quaternary alloy. $12,14,19,21$

According to Refs. 10 and 25, there is a linear correlation between $\Phi_{B O}$ and $n$ as evidence of the Gaussian distribution of a barrier height between the metal and the semiconductor. Therefore, $\Phi_{B O}$ vs $n$ plots for the $(\mathrm{Ni} / \mathrm{Pt}) \mathrm{SCs}$ on AlInGaN quaternary alloy were also drawn and represented in Figs. 5(a) and 5(b), respectively. In Figs. 5(a) and 5(b), it can be seen that there is a good linear correlation between $\Phi_{B O}$ and $n$ and it shows two linear regions that correspond to low and intermediate temperatures. The extrapolation of the $\Phi_{B 0^{-}} n$ plot to $n=1$ for low and intermediate temperatures gives a $\mathrm{BH}$ of approximately 0.62 and $1.4 \mathrm{eV}$ for as-deposited and 0.54 and $1.7 \mathrm{eV}$ for annealed samples, respectively.

The changes in both $n$ and $\Phi_{\mathrm{B} 0}$ with temperature for the SCs on the semiconductor materials could be associated with the existence of a spatial inhomogeneity in the BHs that consists extensively of lower and higher barriers or patches with different areas. ${ }^{17-27,23,24,35}$ In other words, current can preferentially flow through the lower $\mathrm{BH}$ or patches and lead to an important increase in $n$ value.

In order to explain the abnormalities observed in the forward bias $I-V$ characteristics of the as-deposited and annealed (Ni/Pt) SCs on AlInGaN quaternary alloy, we consider the inhomogeneous barrier, consisting of various patches (can be defined as the percolation path) of relatively lower or higher barrier height with respect to a mean value. The total current across a Schottky contact under the 

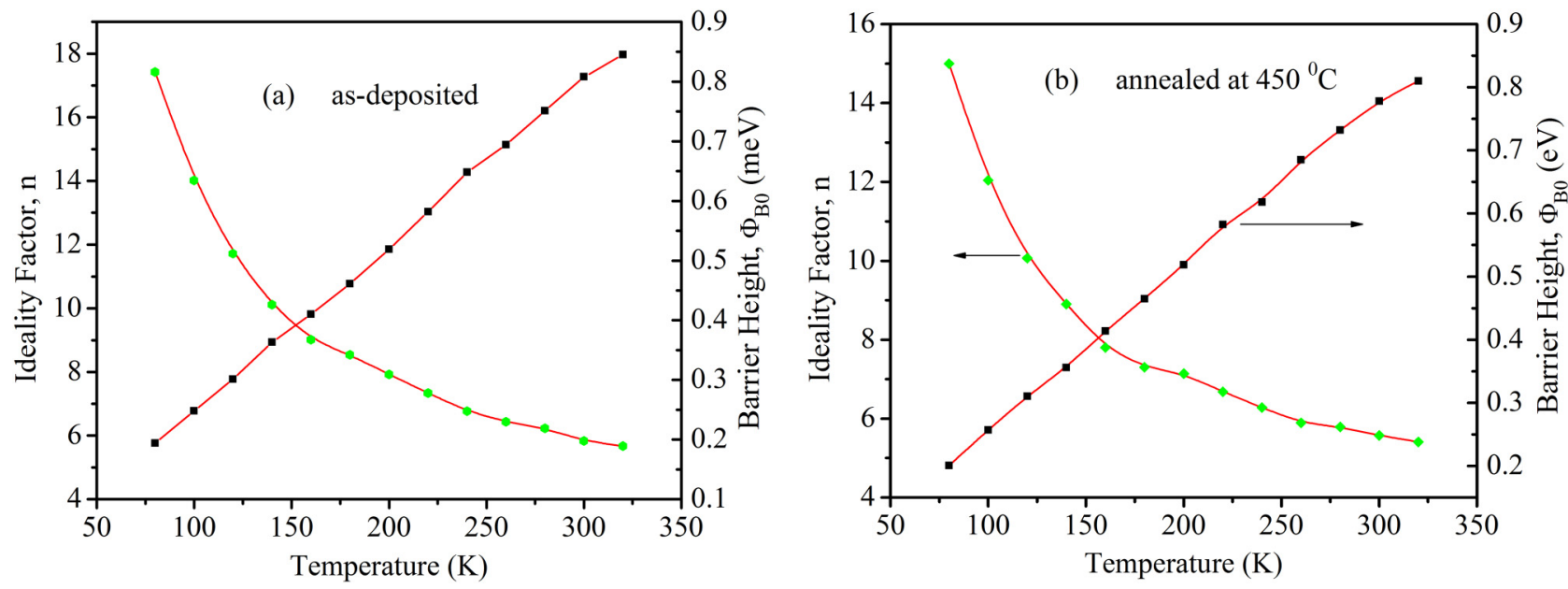

FIG. 3. $n$ vs $T$ and $\Phi_{\mathrm{B} 0}$ vs $T$ plots of the (Ni/Pt/Au) SCs on AlInGaN quaternary alloy; (a) as-deposited and (b) annealed at $450{ }^{\circ} \mathrm{C}$.

inhomogeneous barrier height assumption can be expressed as $^{10-12,28-30}$

$$
I(V)=\int_{-\infty}^{+\infty} I\left(\Phi_{B 0}, V\right) P\left(\Phi_{B 0}\right) d \Phi_{B 0} .
$$

In Eq. (2), $I\left(\Phi_{B 0}, V\right)$ is the current for a barrier of height $\Phi_{B 0}$ at voltage $\mathrm{V}$ based on the TE theory and $P\left(\Phi_{B 0}\right)$ is the normalized distribution function giving the probability of the occurrence of barrier height $\Phi_{B 0}$. The Gaussian distribution function can be written as ${ }^{10-12,25}$

$$
P\left(\Phi_{B 0}\right)=\frac{1}{\sigma_{0} \sqrt{2 \pi}} \exp \left[-\frac{\left(\Phi_{B 0}-\bar{\Phi}_{B 0}\right)^{2}}{2 \sigma_{0}^{2}}\right] .
$$

In Eq. (3), $\bar{\Phi}_{B 0}$ and $\sigma_{0}$ are the mean value of the $\mathrm{BH}$ and the standard deviation from the mean $\mathrm{BH}$, respectively. The current equation under the inhomogeneous barrier height can be derived using GD and $I\left(\Phi_{B 0}, V\right)$ function in Eq. (2) and

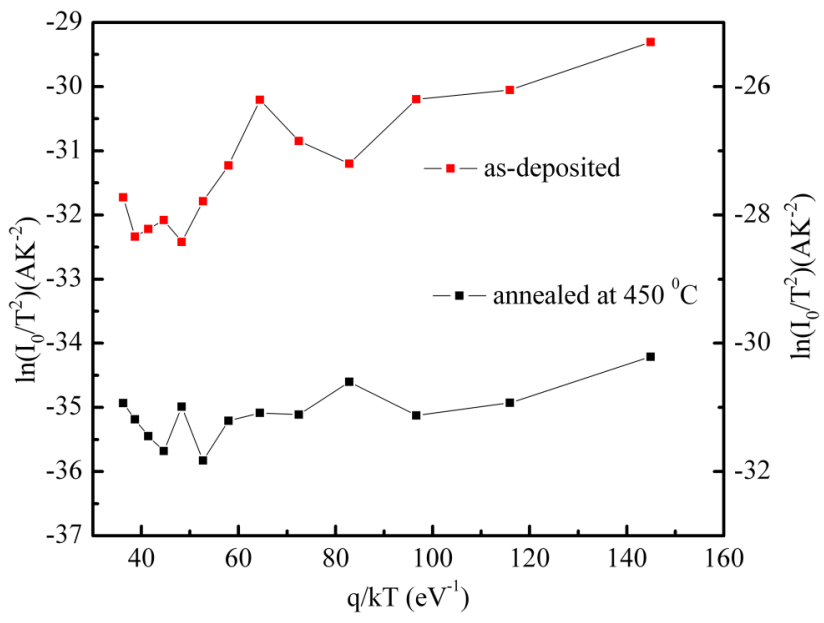

Fig. 4. $\ln \left(I_{0} / T^{2}\right)$ vs $q / k T$ graph of the $(\mathrm{Ni} / \mathrm{Pt} / \mathrm{Au}) \mathrm{SCs}$ on AlInGaN quaternary alloy; (a) as-deposited and (b) annealed at $450{ }^{\circ} \mathrm{C}$. expressed as ${ }^{10-12,25,28-30}$

$$
I(V)=A A^{*} T^{2} \exp \left[-\frac{q \Phi_{\mathrm{ap}}}{k T}\right]\left[\exp \left(\frac{q\left(V-I R_{s}\right.}{n_{\mathrm{ap}} k T}\right)-1\right]
$$

In Eq. (4), $\Phi_{\text {ap }}$ is the apparent barrier height and can be calculated using the formula given below, ${ }^{10-12,25,28-30}$

$$
\Phi_{\mathrm{ap}}=\left[\bar{\Phi}_{B 0}(T=0)-\frac{q^{2} \sigma_{0}^{2}}{2 k T}\right]
$$

On the other hand, apparent ideality factor $\left(n_{\mathrm{ap}}\right)$ in Eq. (4) can be calculated using the equation given below, ${ }^{10-12,25,28-30}$

$$
\left(\frac{1}{n_{\mathrm{ap}}}-1\right)=-\rho_{2}-\left(\frac{q \rho_{3}}{2 k T}\right)
$$

In Eq. 5(b), both $\rho_{2}$ and $\rho_{3}$ are the voltage coefficients that are independent of the temperature, and they quantify the voltage deformation of $\mathrm{BHs}$ distribution and they are the dimensionless coefficients. ${ }^{28-30,40}$ The basis of the GD theory for $\mathrm{BHs}$, modified $\mathrm{BHs}$, and $\sigma_{0}$ is bias dependent. Therefore, in order to explain the above unideal behavior of the forward bias $I-V$ characteristics of these two types of SCs, the GD of $\Phi_{B 0}$ with a mean $\mathrm{BH}$ and $\sigma_{0}$ was employed, as introduced by Ref. 43. On the basis of Eq. 5(a), the value of $\Phi_{\text {ap }}$ vs $q / 2 k T$ plots should be given a linear region yielding $\Phi_{B 0}$ and $\sigma_{0}$ from the $y$-axis intercept and slope of the linear fit, respectively. Similarly, the $n_{\text {ap }}$ vs $q / 2 k T$ plot should be given a linear region yielding $\rho_{2}$ and $\rho_{3}$, respectively. For this purpose, the $\Phi_{\text {ap }}$ vs $q / 2 k T$ and $\left(n^{-1}-1\right)$ vs $q / 2 k T$ plots were drawn and given in Figs. 6 and 7, respectively.

It is clear that the $\Phi_{\text {ap }}$ vs $q / 2 k T$ plot has two distinct linear regions with different slopes for the as-deposited and annealed SCs, implying the presence of the double-GD of $\Phi_{B 0}$ at the M/S interface. From the corresponding calculations using the intercepts and slopes of these straight lines for the as-deposited sample, the mean values of $\Phi_{B 0}$ and $\sigma_{0}$ 

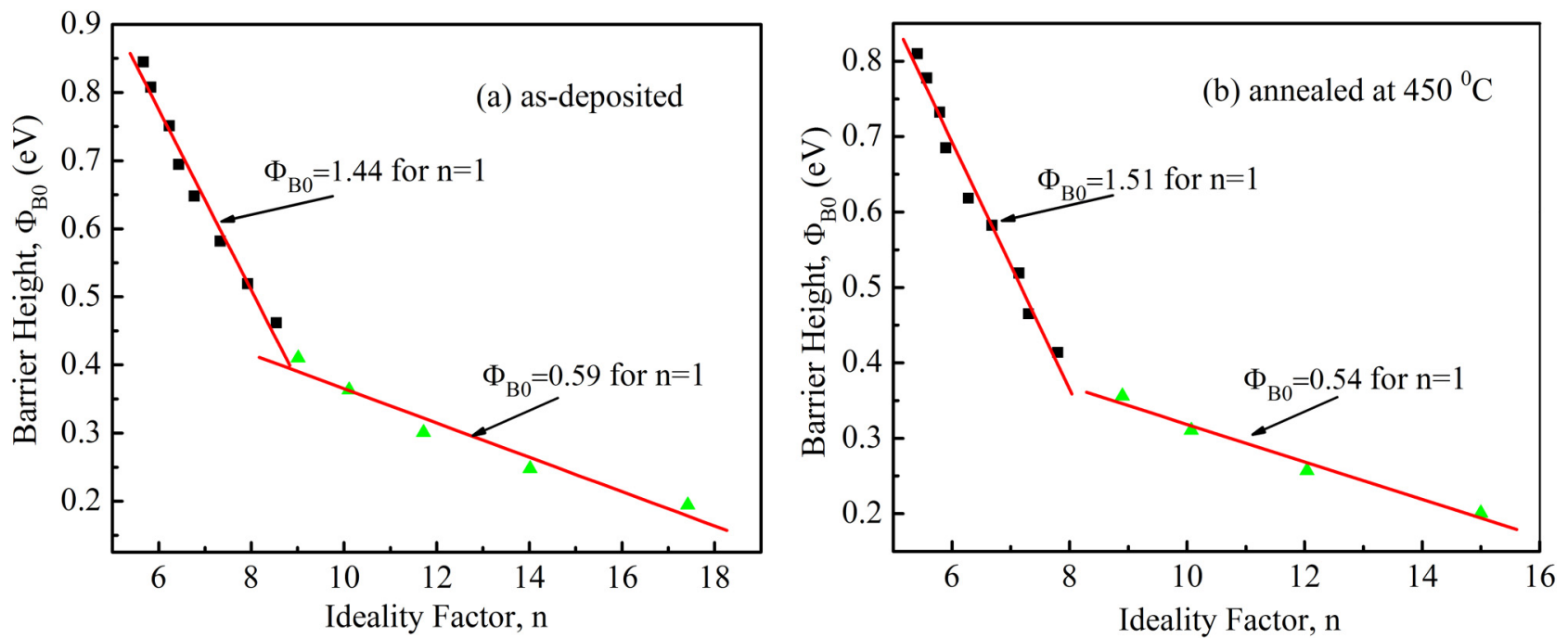

FIG. 5. $\Phi_{B 0}$ vs $n$ plots of the (Ni/Pt/Au) SCs on AlInGaN quaternary alloy; (a) as-deposited and (b) annealed at $450{ }^{\circ} \mathrm{C}$.

were found as $0.61 \mathrm{eV}$ and $77 \mathrm{mV}$ for low and $1.328 \mathrm{~V}$ and $0.17 \mathrm{eV}$ for intermediate temperatures, respectively. On the other hand, the values of $\Phi_{B 0}$ and $\sigma_{0}$ parameters were found as $0.55 \mathrm{eV}$ and $70 \mathrm{mV}$ for low and $0.98 \mathrm{eV}$ and $151 \mathrm{mV}$ for the annealed sample, respectively. The value of $\sigma_{0}$ is a measure of the barrier homogeneity. The low value of $\sigma_{0}$ is corresponding to homogeneity of $\mathrm{BH}$, but the high value of it is corresponding to inhomogeneity of BH. Furthermore, two distinct linear regions with different slopes behavior observed in the $n_{\text {ap }}$ vs $q / 2 k T$ graph for both samples. Similarly, the calculations using the intercepts and slopes of these straight lines were done for the as-deposited sample; the mean values of $\rho_{2}$ and $\rho_{3}$ were found as -0.852 and -0.0013 for low and -0.748 and -0.0043 for intermediate temperatures. After the annealing process, the values of $\rho_{2}$ and $\rho_{3}$ changed as -0.829 and -0.0015 for the low region and -0.755 and -0.0034 for the intermediate temperature region.
Figures 3 and 5-7 have indicated that the values of BHs and $n$ are considerably dependent on temperature and applied voltage in the forward bias region. All of these experimental results for the fabricated $(\mathrm{Ni} / \mathrm{Pt}) \mathrm{SCs}$ on AlInGaN quaternary alloy are indicated that there are two different $\bar{\Phi}_{B 0} \mathrm{~S}$ at low $(T \leq 160 \mathrm{~K})$ and intermediate $(T \geq 180 \mathrm{~K})$ temperatures.

On the other hand, the more reliable value of the $A^{*}$ and mean value of BHs can be calculated from the intercept and slope of the modified Richardson plot that includes the effect of barrier inhomogeneity. For this purpose, the modified $\ln \left(I_{\mathrm{o}} / T^{2}\right)-q^{2} \sigma_{\mathrm{o}}^{2} / 2(k T)^{2}$ vs $q / k T$ plot was drawn and given in Figs. 8(a) and 8(b) for the as-deposited and annealed (Ni/Pt) SCs on AlInGaN quaternary alloy, respectively. Two straight lines for the low and high temperatures regime can be seen from the plots given in Figs. 8(a) and 8(b). Therefore, both the values of $\bar{\Phi}_{B 0}$ and $A^{*}$ were extracted from the slope and intercept of these plots as $0.59 \mathrm{eV}$ and $19.9 \mathrm{~A} \mathrm{~cm}^{-2} \mathrm{~K}^{-2}$ at low and $1.32 \mathrm{eV}$ and $43.3 \mathrm{~A} \mathrm{~cm}^{-2} \mathrm{~K}^{-2}$ at high temperatures
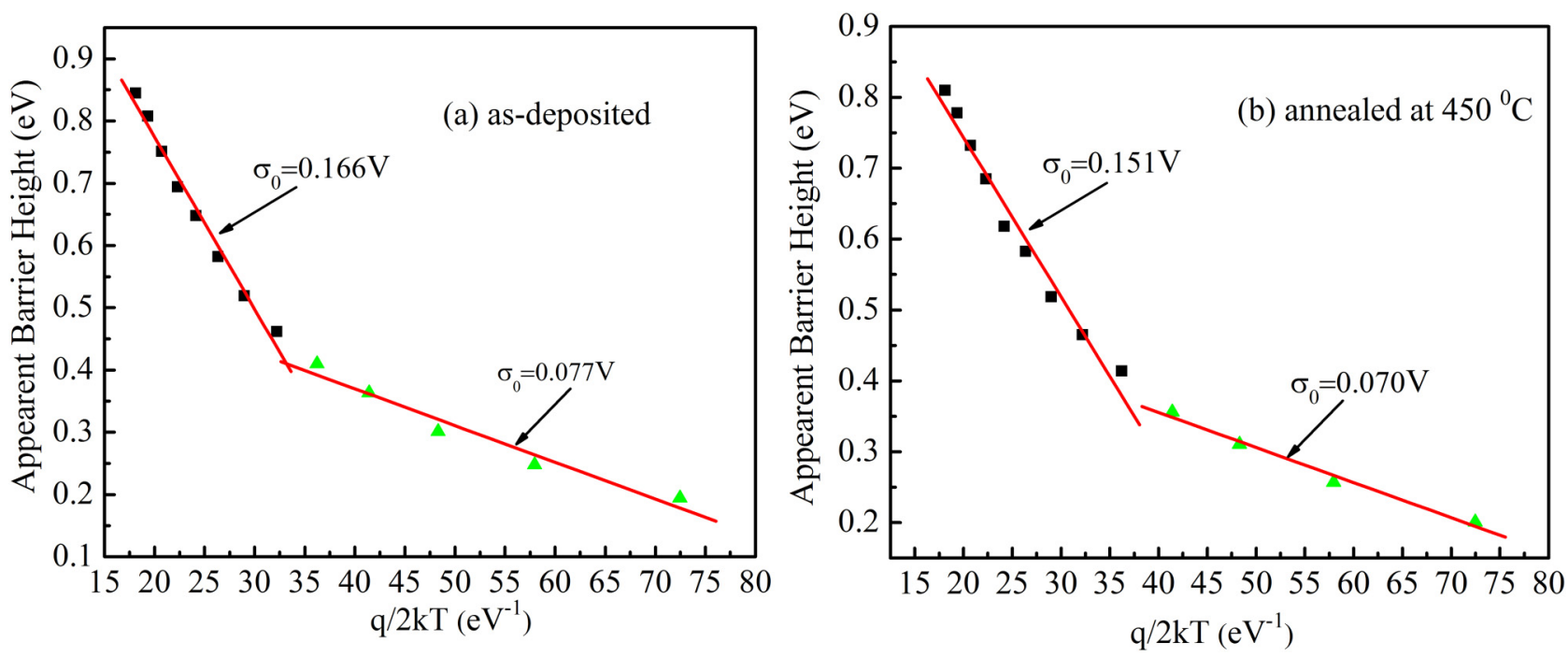

FIG. 6. Apparent barrier height vs $q / 2 k T$ plots of the (Ni/Pt/Au) SCs on AlInGaN quaternary alloy; (a) as-deposited and (b) annealed at $450{ }^{\circ} \mathrm{C}$. 

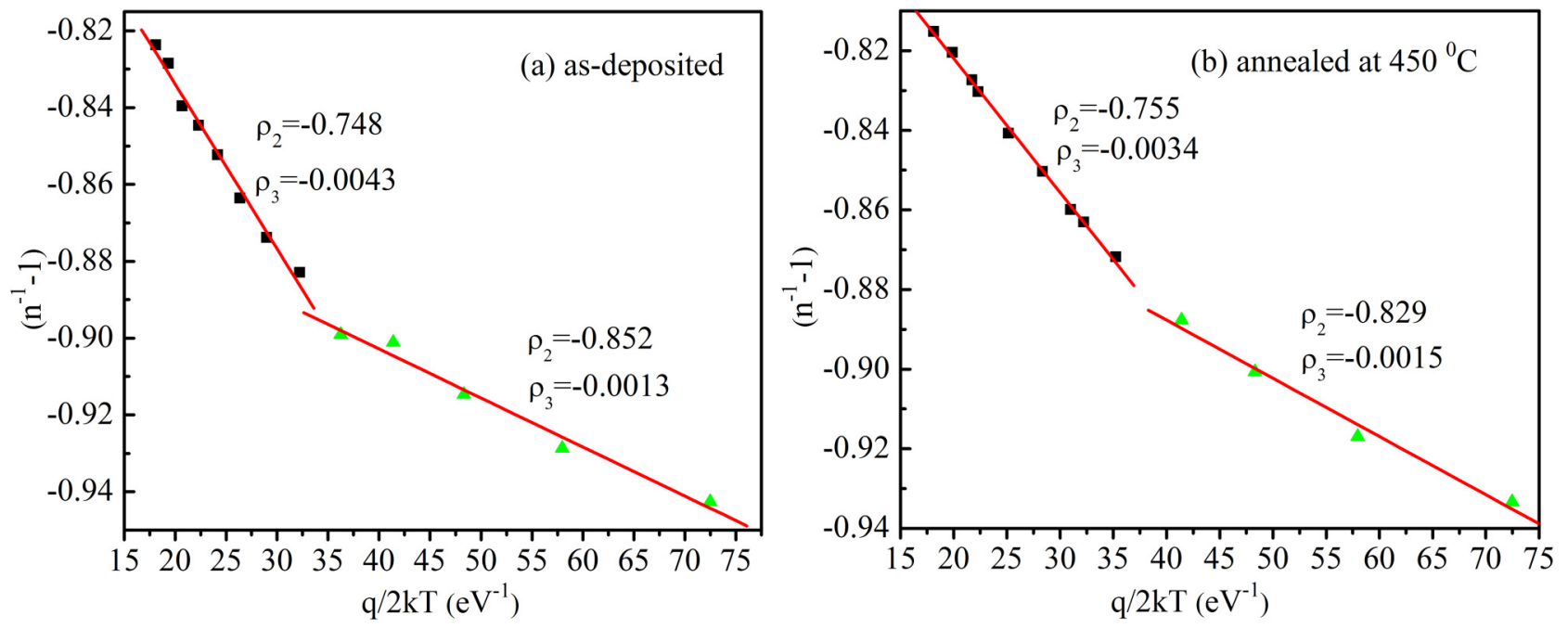

Fig. 7. $\left(n^{-1}-1\right)$ vs $q / 2 k T$ plots of the (Ni/Pt/Au) SCs on AlInGaN quaternary alloy; (a) as-deposited and (b) annealed at $4500^{\circ} \mathrm{C}$.

for the as-deposited sample, respectively. After the annealing process, the $0.37 \mathrm{eV}$ and $19.7 \mathrm{~A} \mathrm{~cm}^{-2} \mathrm{~K}^{-2}$ values were calculated for $\bar{\Phi}_{B 0}$ and $A^{*}$ parameters in the low-temperature region. However, the $1.54 \mathrm{eV}$ and $42.9 \mathrm{~A} \mathrm{~cm}^{-2} \mathrm{~K}^{-2}$ values of the parameters obtained for the annealed sample were in the high temperature region, respectively.

It is clear that the value of $A^{*}$ for as-deposited and annealed samples for intermediate temperatures is very close to the theoretical values of AlInGaN $\left(=44.7 \mathrm{~A} \mathrm{~cm}^{-2} \mathrm{~K}^{-2}\right)$. As a result, we can say that the current-transport mechanism in the fabricated (Ni/Pt) SCs on AlInGaN quaternary alloy can be successfully explained on the basis of TE theory with the double-GD of the $\mathrm{BHs}$ in the whole temperature range. In addition, at low temperatures, tunneling mechanisms may be dominated by another current-transport mechanism in these structures. In other words, the decrease in $\Phi_{B 0}$ and the increase in $n$ with decreasing temperatures are also evidence that the termionic field emission (TFE) at an intermediate temperature or field emission (FE) at a low temperature is possibly the other current-transport mechanisms. ${ }^{15,26}$

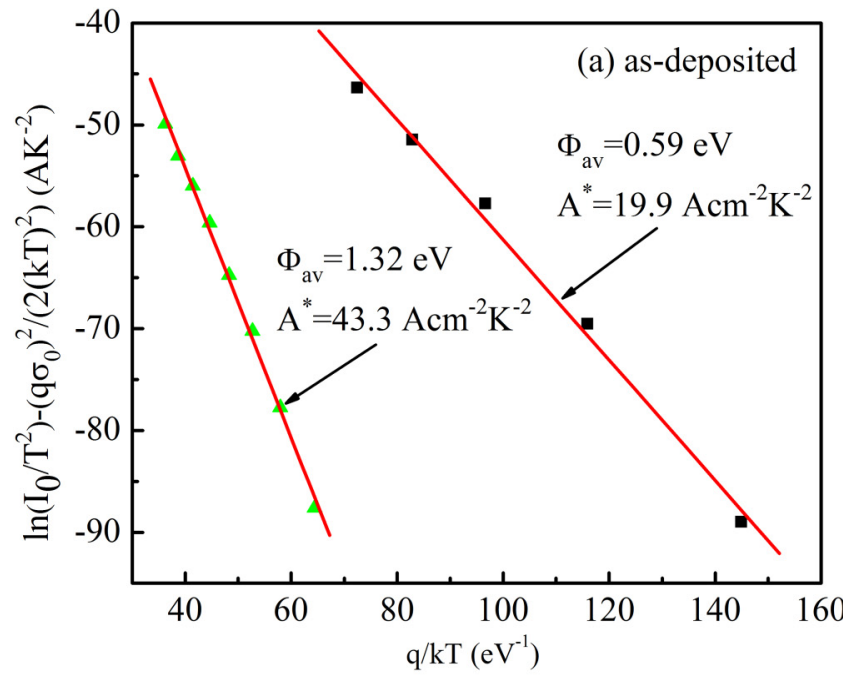

It is clear that the values of $\Phi_{B 0}$ increase with increasing temperature for the as-deposited and annealed SCs and that is also in agreement with what is reported for the negative temperature coefficient of the bandgap of the semiconductor or ideal diode. This result shows that the current-conduction mechanism in the as-deposited and annealed (Ni/Pt) SCs on AlInGaN quaternary alloy deviates considerably from the pure TE theory especially at low temperature. It is assumed that, at higher temperatures, the TE and GR theories dominate, but with tunneling at lower temperatures. On the other hand, when there is a tunneling mechanism, including TFE or FE, it is valid that the relationship for the forward bias current-voltage can be expressed as follows: ${ }^{27,39}$

$$
\begin{aligned}
I & =I_{\text {tun }}\left[\exp \left(\frac{q\left(V-I R_{s}\right.}{E_{0}}\right)-1\right] \text { with } n_{\text {tun }} \\
& =\frac{E_{00}}{k T} \cot \mathrm{h}\left(\frac{E_{00}}{k T}\right)=\frac{E_{0}}{k T} .
\end{aligned}
$$

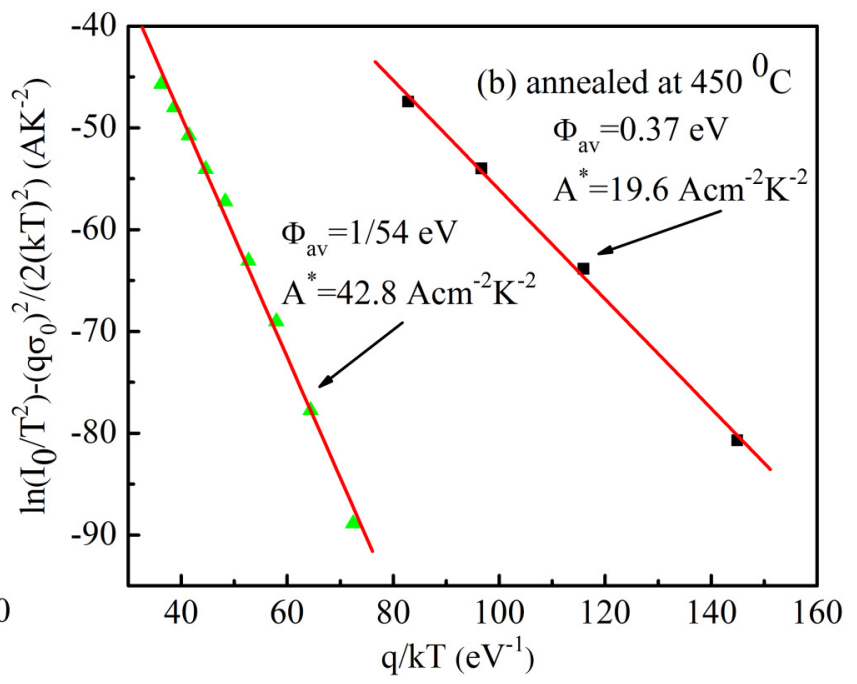

FIG. 8. Modified Richardson plots of the (Ni/Pt/Au) SCs on quaternary AlInGaN alloy; (a) as-deposited and (b) annealed at $450{ }^{\circ} \mathrm{C}$. 

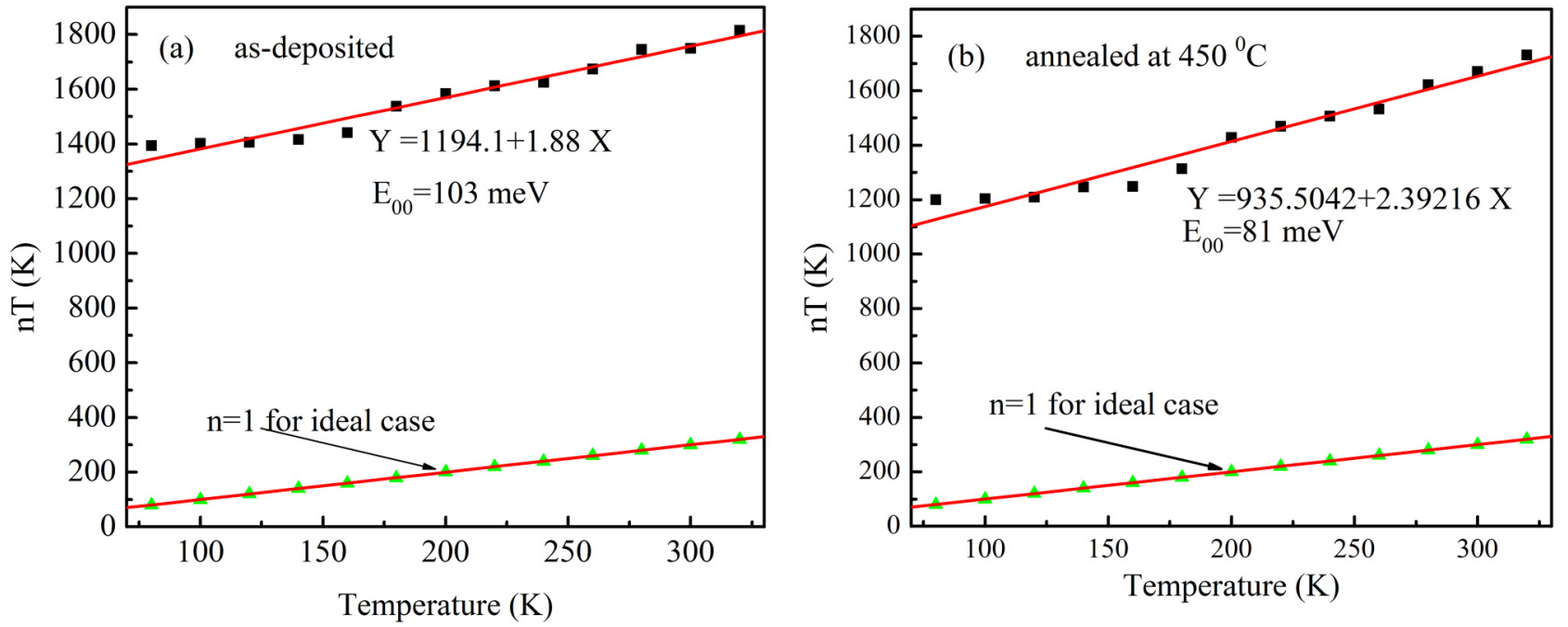

FIG. 9. $n T / q$ vs $T / q$ plots of the (Ni/Pt/Au) SCs on AlInGaN quaternary alloy; (a) as-deposited and (b) annealed at $450{ }^{\circ} \mathrm{C}$.

In Eq. 6(a), $E_{00}$ is the characteristic tunneling energy, which is related to the tunnel effect transmission probability,

$$
E_{00}=\frac{h}{4 \pi}\left(\frac{N_{D}}{m_{e}^{*} \varepsilon_{s}}\right)^{1 / 2} .
$$

In Eq. 6(b), $m_{e}^{*}$ is the effective mass of electron, $\varepsilon_{s}\left(=11.8 \varepsilon_{0}\right.$ for AlInGaN layer) is the dielectric permittivity of semiconductor, and $\varepsilon_{0}\left(=8.85 \times 10^{-12} \mathrm{~F} / \mathrm{m}\right)$ is the permittivity of free space. It is well known that the TFE and FE theories should be dominated when $E_{00} \approx k T / q$ and $E_{00} \gg k T / q$, respectively. For this purpose, $n T$ vs $T$ plot of the $(\mathrm{Ni} / \mathrm{Pt}) \mathrm{SCs}$ on AlInGaN quaternary alloy as-deposited and annealed was drawn and represented in Figs. 9(a) and 9(b), respectively. The value of $E_{00}$ was calculated to be 0.10 and $0.08 \mathrm{eV}$ for as-deposited and annealed samples, respectively. In our case, as can be seen in Figs. 9(a) and 9(b), besides the TE with inhomogeneous barrier height, there can be another current mechanism, such as FE, which is dominated at low temperatures $(T \leq 160 \mathrm{~K})$, but TFE becomes dominant after $180 \mathrm{~K}$.

The existence of series resistance $\left(R_{s}\right)$ for an electronic device can also cause a serious error in the extraction of electrical parameters and leads to a deviation from the linearity of the forward bias $I-V$ plots at enough high bias voltages. Since an electronic device has both $R_{s}$ and native or deposited interfacial layer, the applied bias voltage on the device will be shared by an $R_{s}$, interfacial layer that is inserted between the metal and the semiconductor and a depletion layer of the device or SBD. However, the low value of $R_{S}$ can be accomplished either by having a low SBH between the metal and the semiconductor or by enhancing the tunneling through the SBH by using heavy doped semiconductors $\left(\geq 10^{17} \mathrm{~cm}^{-3}\right)$. In general, the value of $R_{s}$ can originate from the ohmic contact to the semiconductor, the contact made by the probe wire to the gate or rectifier contact, the bulk resistance of the semiconductor, a dirt film or particulate matter at the back contact interface and extremely nonuniform doped atoms in the semiconductor.
There are various methods reported in the literature for the estimation of the $R_{s}$ from the forward bias $I-V$ data, such as Ohm's law, Norde, ${ }^{44}$ Cheung and Cheung, ${ }^{45}$ and modified Norde functions. ${ }^{46}$ Among them, the simplest as well as most accurate and reliable one is the modified Norde function. Norde proposed an alternative method to determine the $R_{s}$ and barrier height based on TE theory which is valid even for the higher values of the ideality factor from the deviation from the linear part of the $\ln \mathrm{I}-\mathrm{V}$ plot for each temperature. On the other hand, the value of BHs and $R_{s}$ may be different from the method to the other method due to the nature of the calculation method and applied bias voltage range. In this study, the values of $R_{s}$ and $\mathrm{BH}$ were obtained from the modified Norde method by Ref. 46. According to Bohlin, an alternative easy method to determine the $\mathrm{BH}\left(\Phi_{B}\right)$ and $R_{S}$ can be expressed as

$$
F(V)=\frac{V}{\gamma}-\frac{k T}{q}\left[\ln \left(\frac{I(V)}{A A^{*} T^{2}}\right)\right]
$$

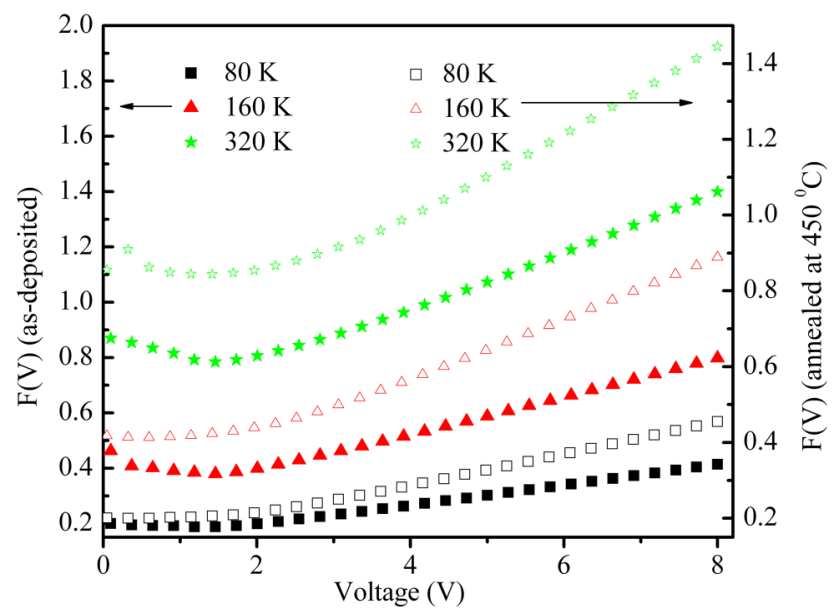

FIG. 10. Modified Norde functions of the (Ni/Pt/Au) SCs on AlInGaN quaternary alloy; (a) as-deposited and (b) annealed at $450{ }^{\circ} \mathrm{C}$. 
TABLE II. Temperature dependent values of the parameters of $V_{m}, I_{m}, F_{m}, R_{s}$, and $\Phi_{B 0}$ for the as-deposited and annealed SCs on AlInGaN quaternary alloy.

\begin{tabular}{|c|c|c|c|c|c|c|c|c|c|c|}
\hline \multirow[b]{2}{*}{$T(\mathrm{~K})$} & \multicolumn{5}{|c|}{ As-deposited } & \multicolumn{5}{|c|}{ Annealed at $450^{\circ} \mathrm{C}$} \\
\hline & $\begin{array}{l}V_{m} \\
(\mathrm{~V})\end{array}$ & $\begin{array}{c}I_{m} \\
(\mu \mathrm{A})\end{array}$ & $\begin{array}{c}F_{m} \\
(\mathrm{mV})\end{array}$ & $\begin{array}{c}R_{s} \\
(\mathrm{k} \Omega)\end{array}$ & $\begin{array}{l}\Phi_{B 0} \\
(\mathrm{eV})\end{array}$ & $\begin{array}{l}V_{m} \\
(V)\end{array}$ & $\begin{array}{c}I_{m} \\
(\mu \mathrm{A})\end{array}$ & $\begin{array}{c}F_{m} \\
(\mathrm{mV})\end{array}$ & $\begin{array}{c}R_{s} \\
(\mathrm{k} \Omega)\end{array}$ & $\begin{array}{l}\Phi_{B 0} \\
(\mathrm{eV})\end{array}$ \\
\hline 80 & 1.348 & 10.5 & 187 & 5.72 & 0.24 & 1.398 & 8.8 & 201 & 11.80 & 0.25 \\
\hline 110 & 1.398 & 12.3 & 233 & 4.92 & 0.30 & 1.398 & 10.6 & 257 & 9.80 & 0.30 \\
\hline 120 & 1.398 & 14.1 & 280 & 4.30 & 0.36 & 1.648 & 12.1 & 310 & 8.61 & 0.37 \\
\hline 140 & 1.448 & 15.6 & 330 & 3.91 & 0.42 & 1.548 & 13.2 & 356 & 8.14 & 0.41 \\
\hline 160 & 1.448 & 16.5 & 379 & 3.77 & 0.49 & 1.498 & 14.1 & 414 & 7.63 & 0.47 \\
\hline 180 & 1.448 & 18.3 & 418 & 3.62 & 0.53 & 1.698 & 15.1 & 465 & 7.51 & 0.54 \\
\hline 200 & 1.398 & 19.1 & 468 & 3.58 & 0.59 & 1.648 & 16.7 & 519 & 7.38 & 0.58 \\
\hline 220 & 1.448 & 19.3 & 533 & 3.60 & 0.66 & 1.498 & 17.4 & 583 & 7.28 & 0.63 \\
\hline 240 & 1.684 & 19.4 & 595 & 3.62 & 0.76 & 1.248 & 17.8 & 618 & 7.30 & 0.68 \\
\hline 260 & 1.684 & 19.4 & 640 & 3.72 & 0.81 & 1.098 & 18.0 & 685 & 7.34 & 0.73 \\
\hline 280 & 1.699 & 20.0 & 707 & 3.76 & 0.89 & 1.248 & 18.6 & 732 & 7.52 & 0.77 \\
\hline 300 & 1.448 & 19.3 & 744 & 3.91 & 0.91 & 1.498 & 18.3 & 778 & 7.88 & 0.81 \\
\hline 320 & 1.448 & 19.0 & 784 & 4.12 & 0.95 & 1.598 & 17.8 & 810 & 8.39 & 0.85 \\
\hline
\end{tabular}

In Eq. (7), $\gamma$ is a dimensionless integer. Norde $^{44}$ found that the $F(\mathrm{~V})$ vs $V$ plot had the form of a curve with a minimum point. He further developed an equation describing the special relationship between $I$ and $V$ at the minimum point and this equation can be used to determine the contact parameter values of $\Phi_{B}$ and $R_{s}$. Also, the $F(\mathrm{~V})$ vs $V$ plot in the modified Bohlin methods had a minimum point and, similar to the Norde methods, contact parameters can be obtained by solving the equations of the minimum points.

The $F(\mathrm{~V})$ vs $V$ plots for each temperature were drawn by using Eq. (7) for the (Ni/Pt) as-deposited and annealed SCs on AlInGaN quaternary alloy and were given in Fig. 10, respectively. As can be seen in these figures, $F(\mathrm{~V})$ vs $V$ plot has a minimum for each temperature. According to the Norde method, the values of $R_{s}$ and $\Phi_{B 0}$ can be obtained from the expressed following relation, respectively: ${ }^{45}$

$$
\begin{aligned}
& R_{s}=\frac{k T(\gamma-n)}{q I_{0}}, \\
& \Phi_{B 0}=F\left(V_{0}\right)+\frac{V_{0}}{\gamma}-\frac{k T}{q},
\end{aligned}
$$

where $n$ value is obtained from the plot of the $\ln I$ vs $V$. $F\left(V_{0}\right)$ is the minimum value of the $F(\mathrm{~V})-V$ plot and $V_{0}$ and $I_{0}$ are the corresponding voltage and current values for any temperature, respectively. For $n=1$ and $\alpha=2$, Eqs. (7)-(9) are the same for the normal Norde method given in Ref. 43. The calculated values of $R_{S}$ and $\Phi_{B 0}$ for each temperature were given in Table II.

As can be seen in Tables I and II, there is some difference between the values of $\mathrm{BH}$ obtained from the $I-V$ and Norde methods. However, in general, by comparing the experimental results, the $\mathrm{BH}$ values that are obtained from the linear part of the $\ln I-V$ plot and Norde functions are almost consistent with each other. The discrepancy between BHs obtained from the Norde and $I-V$ methods can be attributed to the nature of the calculation method and the applied bias voltage effect. The high value of $R_{s}$ may be due to insufficient free charge carriers at low temperature, but the increase in temperature leads to an increase in charge carriers (electrons and holes), which results in a decrease in $R_{s}$. The value of $\mathrm{BH}$ at low temperatures $(\mathrm{T} \leq 200 \mathrm{~K})$ for both as-deposited and annealed samples is in good agreement, but at high temperatures $(\geq 200 \mathrm{~K})$ the value of $\mathrm{BH}$ for an annealing sample becomes lower than the as-deposited sample.

\section{CONCLUSION}

The current-transport mechanisms of the as-deposited and annealed at $450{ }^{\circ} \mathrm{C}(\mathrm{Ni} / \mathrm{Pt})$ Schottky contacts on AlInGaN quaternary alloys have been investigated in the temperature range of $80-320 \mathrm{~K}$. The obtained experimental results indicated that the value of $\Phi_{B 0}$ decreased while the value of $n$ increased with decreasing temperature in both samples. Such behavior of the $\mathrm{BH}$ and higher values of $n$ especially at low temperature could be associated with the nature of inhomogeneous $\mathrm{BH}$ consisting of a combination of low and high barriers or patches between the metal and the semiconductor. The $\Phi_{B o}-n, \Phi_{B o}-q / 2 k T$, and $n^{-1}-q / 2 k T$ plots have two distinct linear regions with different slopes that correspond to the low $(80-160 \mathrm{~K})$ and high $(180-320 \mathrm{~K})$ temperatures. These plots are evidence of the existence of the double-GD of $\mathrm{BH}$ in these structures that have $\bar{\Phi}_{B o}$ and $\sigma_{o}$. On the other hand, to obtain a more reliable value of the $A^{*}$ and the mean value of $\mathrm{BH}$, the modified Richardson plot was drawn by using the experimental values of $\sigma_{\mathrm{o}}$. Therefore, both the values of $\bar{\Phi}_{B 0}$ and $A^{*}$ were extracted from the slope and the intercept of these plots as $0.59 \mathrm{eV}$ and $19.9 \mathrm{~A} \mathrm{~cm}^{-2} \mathrm{~K}^{-2}$ at low and $1.32 \mathrm{eV}$ and $43.3 \mathrm{~A} \mathrm{~cm}^{-2} \mathrm{~K}^{-2}$ at high temperatures before annealing, respectively. After annealing, the values were $0.37 \mathrm{eV}$ and 19.7 $\mathrm{A} \mathrm{cm}^{-2} \mathrm{~K}^{-2}$ at low and $1.54 \mathrm{eV}$ and $42.9 \mathrm{~A} \mathrm{~cm}^{-2} \mathrm{~K}^{-2}$ at high temperatures, respectively. It is clear that the value of $A^{*}$ before and after annealing for intermediate temperatures is close to the theoretical value of AlInGaN $\left(=44.7 \mathrm{~A} \mathrm{~cm}^{-2} \mathrm{~K}^{-2}\right)$. 
In conclusion, the current-transport mechanism in the fabricated $(\mathrm{Ni} / \mathrm{Pt} / \mathrm{Au}) \mathrm{SCs}$ on a quaternary AlInGaN epilayer can be successfully explained based on TE theory with the double-GD of the BHs in the whole temperature range.

\section{ACKNOWLEDGMENTS}

This work is supported by the TUBITAK under Project No. 116F041. One of the authors (E.O.) also acknowledges partial support from the Turkish Academy of Sciences.

${ }^{1}$ E. A. Jones, F. Wang, and D. Costinett, IEEE J. Emerg. Sel. Top. Power Electron. 4, 707 (2016).

${ }^{2}$ K. Ahi, Opt. Eng. 56, 090901 (2017).

${ }^{3}$ R. Wang et al., IEEE Electron Device Lett. 32, 1215 (2011).

${ }^{4}$ T. Lim, R. Aidam, P. Waltereit, T. Henkel, R. Quay, R. Lozar, T. Maier, L. Kirste, and O. Ambacher, IEEE Electron Device Lett. 31, 671 (2010).

${ }^{5}$ B. Reuters, A. Wille, N. Ketteniss, H. Hahn, B. Hollander, M. Heuken,

H. Kalisch, and A. Vescan, J. Electron. Mater. 42, 826 (2013).

${ }^{6}$ H. Hirayama, J. Appl. Phys. 97, 091101 (2005).

${ }^{7}$ S. Karboyan et al., Microelectron. Reliab. 53, 1491 (2013).

${ }^{8}$ F. Lee, L.-Y. Su, C.-H. Wang, Y.-R. Wu, and J. Huang, IEEE Electron Device Lett. 36, 232 (2015).

${ }^{9}$ D. Marcon et al., IEEE Int. Electron Devices Meeting 472, 20.3 .1 (2010).

${ }^{10}$ R. F. Schmitsdrof, T. U. Kampen, and W. Mönch, J. Vac. Sci. Technol. B 15, 1221 (1997).

${ }^{11}$ R. T. Tung, Mater. Sci. Eng. R Rep. 35, 1 (2001).

${ }^{12}$ J. H. Werner and H. H. Güttler, J. Appl. Phys. 69, 1522 (1991).

${ }^{13}$ J. P. Sulvian, R. T. Tung, M. R. Pinto, and W. R. Graham, J. Appl. Phys. 70, 7403 (1991).

${ }^{14}$ L. Huang, Superlattices Microstruct. 100, 648 (2016).

${ }^{15}$ E. Arslan, Ş. Altındal, S. Özçelik, and E. Ozbay, Semicond. Sci. Technol. 24, 075003 (2009).

${ }^{16}$ K. Moraki, S. Bengi, S. Zeyrek, M. M. Bülbül, and Ş. Altındal, J. Mater. Sci.: Mater. Electron. 28, 3987 (2017).

${ }^{17}$ A. Kaya, S. Demirezen, H. Tecimer, and Ş. Altındal, Adv. Polym. Technol. 33, 21442 (2014).

${ }^{18}$ B. L. Sharma, Metal-Semiconductor Schottky Barrier Junctions and Their Applications (Plenum, New York, 1984).

${ }^{19}$ M. A. Laurent, G. Gupta, D. J. Suntrup III, and S. P. DenBaars, J. Appl. Phys. 119, 064501 (2016).

${ }^{20}$ H. Tecimer, A. Türüt, H. Uslu, S. Altındal, and I. Uslu, Sens. Actuators A 199, 194 (2013).
${ }^{21}$ S. Chand and J. Kumar, Semicond. Sci. Technol. 11, 1203 (1996).

${ }^{22}$ Ç. Ş. Güçlü, A. F. Özdemir, and Ş. Altindal, Appl. Phys. A 122, 1032 (2016).

${ }^{23}$ V. Rajagopal Reddy, V. Janardhanam, C. H. Leem, and C. J. Choi, Superlattices Microstruct. 67, 242 (2014).

${ }^{24}$ S. Altındal Yeriskin, M. Balbası, S. Demirezen, Indian J. Phys. 91, 421 (2017).

${ }^{25}$ R. T. Tung, Appl. Phys. Lett. 58, 2821 (1991).

${ }^{26}$ M. Garg, A. Kumar, S. Nagarajan, M. Sopanen, and R. Singh, AIP Adv. 6, 015206 (2016).

${ }^{27}$ E. Arslan, Ş. Altındal, S. Özçelik, and E. Ozbay, J. Appl. Phys. 105, 023705 (2009).

${ }^{28}$ L. Fang, W. Tao, S. Bo, H. Sen, L. Fang, M. Nan, X. F. Jun, W. Peng, and Y. J. Quan, Chinese Phys. B 18, 1618 (2009).

${ }^{29}$ H. Korkut, N. Yildirim, and A. Turut, Physica B 404, 4039 (2009).

${ }^{30}$ N. Yildirim, H. Dogan, and H. Korkut, Int. J. Modern Phys. B 23, 5237 (2009).

${ }^{31}$ R. Khanna, S. J. Pearton, F. Ren, and I. Kravchenko, Appl. Surf. Sci. 252, 5814 (2006).

${ }^{32}$ V. R. Reddy, M. Ravinandan, P. K. Rao, and C.-J. Choi, J. Mater. Sci.: Mater. Electron. 20, 1018 (2009).

${ }^{33}$ J. Wang, D. G. Zhao, Y. P. Sun, L. H. Duan, Y. T. Wang, S. M. Zhang, H. Yang, S. Zhou, and M. Wu, J. Phys. D: Appl. Phys. 36, 1018 (2003).

${ }^{34}$ T. N. Order, P. Martin, J. Y. Lin, H. X. Jiang, J. R. Williams, and T. Isaacs-Smith, Appl. Phys. Lett. 88, 183505 (2006).

${ }^{35}$ N. Miura, T. Nanjo, M. Suita, T. Oishi, Y. Abe, T. Ozeki, H. Ishikawa, T. Egawa, and T. Jimbo, Solid-State Electron. 48, 689 (2004).

${ }^{36}$ N. Subramaniyam, M. Sopanen, H. Lipsanen, C.-H. Hong, and E.-K. Suh, Jpn. J. Appl. Phys. 50, 030201 (2011).

${ }^{37}$ Y. Liu, H. Jiang, T. Egawa, B. Zhang, and H. Ishikawa, J. Appl. Phys. 99, 123702 (2006).

${ }^{38}$ Y. Liu, T. Egawa, H. Jiang, B. Zhang, H. Ishikawa, and M. Hao, Appl. Phys. Lett. 85, 6030 (2004).

${ }^{39}$ S. M. Sze, and Kwok K. Ng, Physics of Semiconductor Devices, 3rd ed. (John Wiley \& Sons, NJ, 2007).

${ }^{40}$ A. R. Deniz, Z. Çaldıran, Ö. Metin, K. Meral, and Ş. Aydoğan, J. Colloid Interface Sci. 473, 172 (2016).

${ }^{41} \mathrm{H}$. Morkoç, Handbook of Nitride Semiconductors and Devices (WileyVCH Verlag GmbH \& Co. KGaA, Weinheim, 2008), Vol. 1.

${ }^{42}$ Abhishek Motayed and S. Noor Mohammad, J. Chem. Phys. 123, 194703 (2005).

${ }^{43}$ Y. P. Song, R. L. Van Meirhaeghe, W. H. Laflere, and F. Cardon, Solid-State Electron. 29, 633 (1986).

${ }^{44}$ H. Norde, J. Appl. Phys. 50, 5052 (1979).

${ }^{45}$ S. K. Cheung and N. W. Cheung, Appl. Phys. Lett. 49, 85 (1986).

${ }^{46}$ K. E. Bohlin, J. Appl. Phys. 60, 1223 (1986). 